\title{
Antibiotic susceptibility profile of Streptococcus pneumoniae isolated from acute respiratory infection in Dakar: a cross sectional study
}

\author{
Abdoulaye Diop, ${ }^{1}$ Makhtar Camara, ${ }^{1}$ Abdoulaye Seck, ${ }^{2}$ Assane Dieng, ${ }^{1}$ Amadou Diop, ${ }^{1}$ Amary Fall, ${ }^{2}$ \\ Cherif Ibrahima. Khalil Diop, ${ }^{3}$ Djibril Boiro, ${ }^{4}$ Jean Baptisse Niokhor Diouf, ${ }^{5}$ Ibrahima Sene, ${ }^{1}$ \\ Modou Gueye, ${ }^{4}$ Mbayame Niang, ${ }^{2}$ Cheikh Saad Bouh Boye ${ }^{1}$
}

${ }^{1}$ Bacteriology and Virology Laboratory, Le Dantec University Teaching Hospital, Dakar, Senegal; ${ }^{2}$ Medical Virology Unit, Institute Pasteur, Dakar, Senegal; ${ }^{3}$ Laboratory of Renewable Nanomaterial, University of Maine, Orono, ME, USA; ${ }^{4}$ Paediatric Unit, Abass Ndao University Teaching Hospital, Dakar, Senegal; ${ }^{5}$ Paediatric Unit, Roi Baudouin Hospital, Dakar, Senegal

\section{Summary}

Streptococcus pneumoniae is a pathogen causing pneumonia, meningitis, otitis and bacteraemia. Nowadays, S. pneumoniae is developing antibacterial resistance, particularly for those with reduced susceptibility to penicillin. The objective of this study was to assess the susceptibility profile of $S$. pneumoniae strains

Correspondence: Abdoulaye Diop, Cheikh Anta Diop University, CHNU Aristide Le Dantec, Laboratory of Bacteriology-Virology, 30 Avenue Pasteur, BP 7325, Dakar, Senegal.

Tel.: +221775079455

E-mail: laycoumba@yahoo.fr.

Key words: Respiratory tract infections, Streptococcus pneumoniae, Antibiotic susceptibility.

Acknowledgements: The authors would thank GlaxoSmithKline (GSK) who supported for the E-test and identification reagents and all who have contributed to the success of this study.

Contributions: Conceived and designed the experiments: AD, MC, CSBB, MG. Analyzed and interpreted the data: AD, IS, AF. Wrote the first draft of the manuscript: AD, AS, AD, CIKD, MC. Reviewed and approved of the final manuscript: $\mathrm{AD}$, ADie, MC, DB, JBND, CIKD, AS, MN, MG, CSBB.

Conflict of interest: The authors declare no potential conflict of interest.

Funding: none.

Received for publication: 6 October 2018.

Revision received: 26 November 2018.

Accepted for publication: 27 November 2018.

(C) Copyright A. Diop et al., 2018

Licensee PAGEPress, Italy

Microbiologia Medica 2018; 33:7862

doi:10.4081/mm.2018.7862

This article is distributed under the terms of the Creative Commons Attribution Noncommercial License (by-nc 4.0) which permits any noncommercial use, distribution, and reproduction in any medium, provided the original author(s) and source are credited. isolated from acute respiratory infections (ARIs) in children younger than 5 years of age in Dakar, Senegal. S. pneumoniae strains were isolated from broncho-alveolar lavages (BALs), nasopharyngeal swabs, and middle ear secretion from children in the Paediatric Department of Abass Ndao University Teaching Hospital and Paediatric Department of Roi Baudouin Hospital in Dakar, Senegal. The strains were cultivated on Columbia agar supplemented with $5 \%$ of horse blood and gentamicin $(6 \mathrm{mg} / \mathrm{L})$. Antibiotic susceptibility testing was performed using E-test method. A total of 34 strains of $S$. pneumoniae were isolated and identified in this study, among them 7 strains (20.58\%) showed penicillin-resistance. Antibiotics such as amoxicillin/clavulanic acid $\left(\mathrm{MIC}_{90}=0.036 \mu \mathrm{g} / \mathrm{mL}\right)$, cefuroxim $\left(\mathrm{MIC}_{90}=0.38 \mu \mathrm{g} / \mathrm{mL}\right)$, cefixim $\left(\mathrm{MIC}_{90}=1.5 \mu \mathrm{g} / \mathrm{mL}\right.$ ), as well as macrolides (azithromycin $\mathrm{MIC}_{90}=1.5 \mu \mathrm{g} / \mathrm{mL}$, clarithromycin $\mathrm{MIC}_{90}=0.125 \mu \mathrm{g} / \mathrm{mL}$ ) and fluoroquinolone (levofloxacin $\mathrm{MIC}_{90}=1 \mu \mathrm{g} / \mathrm{mL}$, ofloxacin $\mathrm{MIC}_{90} 2$ $\mu \mathrm{g} / \mathrm{mL}$ ) were mostly active. However, all $S$. pneumoniae strains were resistant to sulfamethoxazole/trimethoprim $\left(\mathrm{MIC}_{90}: 32\right.$ $\mu \mathrm{g} / \mathrm{mL})$. Except of $S$. pneumoniae strains penicillin-resistance or reduced susceptibility, most strains were susceptible to $\beta$-lactams antibiotics commonly used in ARI treatment. Continuous surveillance of antimicrobial resistance patterns of pneumococcus strains is still crucial for effective control of ARIs in children.

\section{Introduction}

Streptococcus pneumoniae is one of the most frequent causes of serious invasive infections, such as meningitis, bacteremia and pneumonia and it is the major cause of morbidity and mortality worldwide (7). Pneumonia accounts for $15 \%$ of all deaths of children younger than 5 years of age and it is the single largest infectious cause of death in children worldwide (14). In 2015, the pneumonia killed 920,000 children and is a source of distress, suffering and debilitating long-term health problems for many children (17).

Pneumonia affects children and families everywhere, but is most prevalent in South Asia and sub-Saharan Africa (24).

In Senegal, the mortality rate of children younger than 5 years of age due to pneumonia accounted for $13 \%$ of the total rate (22). $S$. pneumoniae was susceptible to many antibiotics including the $\beta$-lactams, macrolides, fluoroquinolones and vancomycin (12). However, acquired resistance has emerged in recent decades, especially against penicillin and macrolides. The emergence of $S$. pneumoniae strains resistant not only to penicillin, but also to 
other antibiotics, has been reported in the last two decades worldwide and can pose a serious public health challenge (13). Antimicrobial resistance of $S$. pneumoniae is not only a local but also a global problem (11).

The objective of this study was to assess the susceptibility profile of S. pneumoniae strains isolated from ARI's cases in children younger than 5 years of age in Dakar.

\section{Materials and Methods}

\section{Isolation and culture of $S$. pneumoniae}

S. pneumoniae strains were isolated between January 2015 and December 2016, from the Paediatric Department of Abass Ndao University Teaching Hospital and Paediatric Department of Roi Baudouin Hospital in Dakar (Senegal). The strains were isolated from broncho-alveolar lavages (BAL), nasopharyngeal swabs and middle ear secretion in children younger than 5 years of age.

Samples were cultivated using Columbia agar supplemented with $5 \%$ of horse blood and gentamicin $(6 \mathrm{mg} / \mathrm{l})$ (Biorad, Hercules, California, USA).

\section{Identification of the isolated strains}

S. pneumoniae strains were identified if bacterial load was at least $10^{5} \mathrm{CFU} / \mathrm{mL}$.

The identification method was performed using morphology characters, optochin susceptibility, bile solubility and the presence of capsule (10).

\section{Antibiotic susceptibility testing}

The antibiotic susceptibility was carried out using strips ETest $^{\circledR}$ (bioMerieux SA, Lyon) and minimum inhibitory concentration (MIC) was determined according European Committee of Antimicrobial Susceptibility Testing guideline (EUCAST) (5).

Penicillin, amoxicillin/clavulanic acid, cefuroxim, cefixim, azithromycin, clarithromycin, clindamycin, levofloxacin, ofloxacin and sulfamethoxazole/trimethoprim were tested. The quality control for antimicrobial susceptibility testing was performed using the ATCC 49619 strains of S. pneumoniae.

\section{Analysis of results}

The geometric mean values of $\mathrm{MIC}_{50}$ and $\mathrm{MIC}_{90}$ obtained from the antibiotic susceptibility testing were calculated and analyzed using the Whonet 5.6 software (WHO Collaborating Centre for Surveillance of Antimicrobial Resistance, Boston, Massachusetts).

\section{Results}

A total of 34 strains of $S$. pneumoniae were isolated and identified from children under 5 years of age. These strains of S. pneumoniae were tested for antibiotics susceptibility.

\section{Antibiotic susceptibility testing}

Table 1 summarizes the results of the susceptibility testing of S. pneumoniae to commonly used antibiotics in ARIs treatment.

\section{Susceptibility to $\beta$-lactam antibiotics}

$\beta$-lactams were the antimicrobial class mostly active towards $S$. pneumoniae; $20.58 \%$ tested strains showed penicillin $\mathrm{G}$ resistance ( $\mathrm{MIC}_{90}: 0.125 \mu \mathrm{g} / \mathrm{mL}$ ), while amoxicillin and clavulanic acid (AMC) showed a high activity with a very low $\mathrm{MIC}_{90}(0.032 \mu \mathrm{g} / \mathrm{mL})$. In addition, a high cephalosporin activity (97.05\%) was observed (cefuroxime $\mathrm{MIC}_{90}: 0.38 \mu \mathrm{g} / \mathrm{mL}$ and cefixim $\mathrm{MIC}_{90}: 1.5 \mu \mathrm{g} / \mathrm{mL}$ ).

\section{Susceptibility to macrolides}

Clarithromycin ( $\mathrm{MIC}_{90}: 0.125 \mu \mathrm{g} / \mathrm{mL}$ ) and azithromycin $\left(\mathrm{MIC}_{90}: 1.5 \mu \mathrm{g} / \mathrm{mL}\right)$ showed activity rates against $S$. pneumoniae ( $82.35 \%$ and $73.53 \%$ respectively). Clarithromycin was the most active molecule among all tested macrolides.

\section{Susceptibility to fluoroquinolones}

Levofloxacin was active in all tested strains with lower $\mathrm{MIC}_{90}$ $(1 \mu \mathrm{g} / \mathrm{mL})$ compared to ofloxacin ( $\mathrm{MIC}_{90}: 2 \mu \mathrm{g} / \mathrm{mL}$ ).

\section{Susceptibility to other antibiotics}

Clindamycin was active in $97.0 \%$ of strains with low $\mathrm{MIC}_{90}$ $(0.19 \mu \mathrm{g} / \mathrm{mL})$. However, all isolates were resistant to sulfamethoxazole/trimethoprim.

Table 1. Susceptibility rates of $S$. pneumoniae and MIC values (E-test).

\begin{tabular}{|c|c|c|c|c|c|c|c|c|}
\hline Antibiotics & MIC range & $\begin{array}{l}\text { Obtained } \\
\text { MIC } \\
\text { ranges }\end{array}$ & $\begin{array}{c}\text { Critical } \\
\text { values } \\
\text { ( } \mu \mathrm{g} / \mathrm{mL} \text { ) R }\end{array}$ & $\begin{array}{c}\text { Critical } \\
\text { values } \\
(\mu \mathrm{g} / \mathrm{mL}) \mathrm{S}\end{array}$ & $\mathbf{R}(\%)$ & S (\%) & $\mathrm{MIC}_{50}$ & $\mathrm{MIC}_{90}$ \\
\hline Penicillin G & $0.002-32$ & $0.03-16$ & $\mathrm{R} \geq 2$ & $\mathrm{~S} \leq 0.064$ & 20.58 & 79.42 & 0.032 & 0.125 \\
\hline Amoxicillin/clavulanic acid & $0.016-256$ & $0.016-16$ & $\mathrm{R} \geq 8$ & $\mathrm{~S} \leq 2$ & 2.95 & 97.05 & .016 & 0.032 \\
\hline Cefuroxim & $0.016-256$ & $0.016-48$ & $\mathrm{R} \geq 4$ & $\mathrm{~S} \leq 1$ & 2.95 & 97.05 & 0.047 & 0.38 \\
\hline Cefixim & $0.016-256$ & $0.094-256$ & $\mathrm{R} \geq 4$ & $\mathrm{~S} \leq 1$ & 2.95 & 97.05 & 0.38 & 1.5 \\
\hline Levofloxacin & $0.002-32$ & $0.19-2$ & $R \geq 8$ & $\mathrm{~S} \leq 2$ & 0 & 100 & 0.5 & 1 \\
\hline Ofloxacin & $0.002-32$ & $1-16$ & $\mathrm{R} \geq 8$ & $\mathrm{~S} \leq 2$ & 23.53 & 76.47 & 1.5 & 2 \\
\hline Sulfamethoxazole/Trimethoprim & $0.016-256$ & 8-256 & $\mathrm{R} \geq 4$ & $\mathrm{~S} \leq .5$ & 100 & 0 & 3 & 32 \\
\hline Clindamycin & $0.016-256$ & $0.032-1$ & $\mathrm{R} \geq 1$ & $\mathrm{~S} \leq 0.25$ & 2.95 & 97.05 & 0.094 & 0.19 \\
\hline Azithromycin & $0.016-256$ & $0.094-32$ & $\mathrm{R} \geq 2$ & $\mathrm{~S} \leq 0.5$ & 26.47 & 73.53 & 0.5 & 1.5 \\
\hline Clarithromycin & $0.016-256$ & $0.094-3$ & $\mathrm{R} \geq 1$ & $\mathrm{~S} \leq .25$ & 17.65 & 82.35 & 0.064 & 0.125 \\
\hline
\end{tabular}

S: susceptibility; R: resistance; MIC: Minimum Inhibitory Concentration; MIC 50 : Minimum Inhibitory Concentration at which 50\% of the strains are inhibited; MIC90: Minimum Inhibitory Concentration at which 90\% of the strains are inhibited. 


\section{Discussion}

In our study, antibiotic susceptibility patterns of $S$. pneumoniae strains isolated in children younger than 5 years of age with ARIs was assessed. Antimicrobial resistance patterns have been detected with antibiotics used in the clinical practice including $\beta$-lactams, macrolides, fluoroquinolone and sulfamethoxazole/trimethoprim.

The emergence of high-level penicillin-resistance of S. pneumoniae strains complicated seriously infections treatment in the recent years (2).

In our study, $20.58 \%$ of $S$. pneumoniae strains showed resistance to penicillin $\mathrm{G}$.

A similar result was reported from an antibiotic resistance surveillance study carried out between 2002 and 2003 in Turkey (19) showing $25.3 \%$ of penicillin reduced susceptibility rate. Higher prevalence rates of penicillin $G$ resistance were reported from studies performed in Senegal in 2009 (31.3\%) and in 2017 $(33.3 \%)(3,6)$.

Penicillin resistance rates vary widely between African countries, with $57 \%$ prevalence rates in Algeria (6), 48.5\% in Morocco (4), $50.4 \%$ in Tunisia (21), $0.5 \%$ in South Africa (20), $12 \%$ in Ghana (8).

In our study, amoxicillin/clavulanic acid $\left(\mathrm{MIC}_{50}: 0.016\right.$ $\mu \mathrm{g} / \mathrm{mL}$ and $\mathrm{MIC}_{90}: 0.032 \mu \mathrm{g} / \mathrm{mL}$ ) and levofloxacin $\left(\mathrm{MIC}_{50}\right.$ : $0.5 \mu \mathrm{g} / \mathrm{mL}$ and $\mathrm{MIC}_{90}: 1 \mu \mathrm{g} / \mathrm{mL}$ ) were the most active antibiotic against $S$. pneumoniae.

According a study performed in Turkey in 2007, AMC was the most active antibiotic tested against $S$. pneumoniae $(98.7 \%$ ), following by cephalosporins cefprozil (90.6\%) and cefaclor $(78.7 \%)$ (18). In our study, $97.05 \%$ of activity were observed with cefurox$\mathrm{im}\left(\mathrm{MIC}_{90}: 0.38 \mu \mathrm{g} / \mathrm{mL}\right)$ and cefixim $\left(\mathrm{MIC}_{90}: 1.5 \mu \mathrm{g} / \mathrm{mL}\right)$.

Our results are in agreement with data reported in 2017, showing $81.3 \%$ and $75.5 \%$ activity of cefuroxim and cefixim, respectively (3). Ceftaroline fosamil is a broad-spectrum cephalosporin antibiotic with activity against many bacteria, including $S$. pneumoniae (both penicillin-non-susceptible and multi-drug-resistant strains) (14).

In our study, susceptibility to fluoroquinolones showed a full activity of levofloxacin $(100 \%)$ with low $\mathrm{MIC}_{90}(1 \mu \mathrm{g} / \mathrm{mL})$ and ofloxacin activity was $76.47 \%$ with $\mathrm{MIC}_{90}$ equal to $2 \mu \mathrm{g} / \mathrm{mL}$.

Fluoroquinolones were associated with higher success of treatment for severe cases of pneumonia (23). This is similar to results reported from study performed in Dakar in 2017 showing $100 \%$ of susceptibility to levofloxacin (3). Fluoroquinolones demonstrated extremely excellent activity against $S$. pneumoniae in China (25). Ciprofloxacin and moxifloxacin were more active than other fluoroquinolones (16). The worldwide prevalence of $S$. pneumoniae fluoroquinolones resistance is low, although it varies over time, geographic region, age group, and origin of isolate (1).

Therefore, fluoroquinolones could be used as alternative choice in the treatment of $S$. pneumoniae infections (25).

Macrolide resistance frequency varies from a country to another, and a worldwide increase is observed: from $8 \%$ to $22 \%$ over a 10 -year period in Canada and from $7.4 \%$ to $53.7 \%$ over a 20 -year period in Greece (15). In our study, clarithromycin showed good activity with $82.35 \%$ of isolates susceptible, while azithromycin was active in $73.53 \%$ of the strains tested with high $\mathrm{MIC}_{90}(1.5$ $\mu \mathrm{g} / \mathrm{mL})$. In Tunisia, the rates of reduced susceptibility to penicillin, and erythromycin and tetracycline resistance were $60.2 \%, 68.1 \%$ and $38.4 \%$, respectively (15). In China, macrolides including azithromycin, clarithromycin and erythromycin showed lowest activity both against penicillin-non-susceptible Streptococcus pneumoniae (PNSSP) and penicillin-susceptible Streptococcus pneumoniae (PSSP) strains, with very high $\mathrm{MIC}_{90}$ values $(>256$ $\mathrm{mg} / \mathrm{L})(25)$. Increased macrolides resistant strains could be related to the fact that the resistance to penicillin is generally associated with resistance to other antibiotic families, including macrolides, sulfamethoxazole/trimethoprim, and fluoroquinolones (9).

In our study clindamycin showed very good activity with $97.05 \%$ of isolates susceptible; a similar result was obtained in Dakar in 2009 (6). In 2015, a study carried out in the Sarajevo Canton showed high clindamycin and erythromycin resistance (11).

Resistance to sulfamethoxazole/trimethoprim was detected in all isolates tested in our study; this is in agreement with results reported in 2017 in Dakar (3).

\section{Conclusions}

Except penicillin-resistance, most of $S$. pneumoniae strains remained susceptible to $\beta$-lactams mainly used as primary treatment for ARIs. Fluoroquinolones and macrolides showed good activities and could be used as alternative antibiotic therapy.

Continuous surveillance of $S$. pneumoniae susceptibility patterns is required for a better management and prevention of ARIs, particularly in children younger than 5 years of age.

\section{References}

1. Adela G, Balsalobre L, Ardanuy C, et al. Fluoroquinolone Resistance in Penicillin-resistant Streptococcus pneumoniae Clones, Spain. Emerg Infect Dis 2004;10:1751-9.

2. Ahmadi A, Yaghoubi S, Irajian G. Molecular Analysis of PBP1A in Streptococcus pneumoniae Isolated from Clinical and Normal Flora Samples in Tehran, Iran: A Multicenter Study. Microb Drug Resist 2018.

3. Camara M, Dieng A, Diop A, et al. Antibiotic resistance of bacteria responsible of acute respiratory tract infections in children. Microbiol Med 2017;32:6489.

4. Elmdaghri N, Benbachir M, Belabbes H, et al. Changing epidemiology of pediatric Streptococcus pneumoniae isolates before vaccine introduction in Casablanca (Morocco). Vaccine 2012;30:46-50.

5. EUCAST (European Committee Antimicrobial Susceptibility Testing). V1. 2015.

6. Gueye A, Boye CS , Hounkponou1 E, et al. Antimicrobial susceptibility of select respiratory tract pathogens in Dakar, Senegal. J Infect Dev Ctries 2009;3:660-6.

7. Hecini-Hannachi A, Bentchouala C, Lezzar A, et al. Serotypes and antimicrobial resistance of invasive Streptococcus pneumoniae isolates from East Algeria (2005-2011). Afr J Microb Res 2013;8:167-77.

8. Holliman RE, Liddy H, Johnson JD, et al. Epidemiology of invasive pneumococcal disease in Kumasi, Ghana. Trans R Soc Trop Med Hyg 2007;101:405-13.

9. Jacobs MR, Felmingham D, Appelbaum PC, et al. The Alexander Project 1998-2000: susceptibility of pathogens isolated from community-acquired respiratory tract infection to commonly used antimicrobial agents. J Antimicrob Chemother 2003:229-46.

10. Kaijalainen T. The Identification of Streptococcus pneumoniae. Natl Public Health Institute 2006;76.

11. Karcic E, Aljicevic M, Bektas S, et al. Antimicrobial Susceptibility/Resistance of Streptococcus Pneumoniae. Mater Sociomed 2015;27:180-4. 
12. Karpanoja P Antimicrobial Resistance in The Major Respiratory Tract Pathogens - Methods and Epidemiology. Faculty of Biological and Environmental Sciences. University of Helsinki Academic Dissertation. 2017.

13. Ktari S, Ben Ayed N, Jmal I, et al. Clinical levofloxacin resistant Streptococcus pneumoniae isolates in North Africa. Global Antimicrob Res 2018;12:181-2.

14. Mathur S, Fuchs A, Bielicki J, et al. Antibiotic use for community-acquired pneumonia in neonates and children: WHO evidence review. Paediatr Int Child Health 2018;38:66-75.

15. Raddaoui A, Ben Tanfous F, Chebbi Y, et al. High prevalence of multidrug resistant international clones among macrolide resistant Streptococcus pneumoniae strains in immunocompromised Patients in Tunisia. Int J Antimicrob Agents 2018:30117-1.

16. Robert P. Fluoroquinolone Positioning in Hospital Antimicrobial Stewardship Programs. US Pharm 2007;32:10-7.

17. Save the Children. Fighting For Breath: A call to action on childhood pneumonia. Report 2017.

18. Sener B, Tunçkanat F, Ulusoy S, et al. A survey of antibiotic resistance in Streptococcus pneumoniae and Haemophilus influenzae in Turkey, 2004-2005. J Antimicrob Chemother 2007;60:587-93.

19. Shibl A, Daniels J, Sievers J. Antimicrobial resistance among Streptococcus pneumoniae and Haemophilus influenzae from Africa and the Middle East: 2002/2003 winter season. Clin Microbiol Infect 2004;10:111.
20. Silberbaue EJ, Ismai N, Von-Gottberg A, et al. Serotype and antimicrobial profile distribution of invasive pneumococcal isolates in the pre-vaccine introduction era in Pretoria, South Africa 2005 through 2009. Diagn Microbiol Infect Dis 2011;71:309-11.

21. Smaoui H, Amri J, Hajji N, et al. Antimicrobial susceptibility and serotype distribution of Streptococcus pneumoniae isolates in children in Tunis. Arch Pediatr 2009;6:220-6.

22. USAID/ MCHIP. Integrated Community Case Management of Childhood Illness: Documentation of Best Practices and Bottlenecks to Program Implementation in Senegal. Revised and Submitted 2 September 2011, 1.

23. Vardakas KZ, Siempos II, Grammatikos A, et al. Respiratory fluoroquinolones for the treatment of community-acquired pneumonia: a meta-analysis of randomized controlled trials. CMAJ 2008;179:1269-77.

24. World Health Organization. Revised WHO classification and treatment of childhood pneumonia at health dacilities - evidence summaries. Geneva: WHO; 2015.

25. Zhang Y, Zhang F, Hui Wang H, et al. Antimicrobial susceptibility of Streptococcus pneumoniae, Haemophilus influenzae and Moraxella catarrhalis isolated from community-acquired respiratory tract infections in China: Results from the CARTIPS Antimicrobial Surveillance Program. J Global Antimicrob Res 2016:36-41. 